\title{
The Law of Growth of Nitrided Layer in 31CrMoV9 Steel
}

\author{
N. SYla ${ }^{a}$, F. Aliaj ${ }^{a, *}$ AND B. DALiPi ${ }^{b}$ \\ ${ }^{a}$ University of Prishtina, Department of Physics, Mother Theresa Str. 5, 10000 Prishtina, Kosova \\ ${ }^{b}$ University Kadri Zeka, Faculty of Education, Zija Shemsiu Str. nn, 60000 Gjilan, Kosova
}

\begin{abstract}
The law of growth of nitrided layers produced by gaseous nitriding of 31CrMoV9 alloy steel at different process parameters is described. 31CrMoV9 steel specimens were subjected to nitriding process in ammonia gas at three different temperatures: 510,550 and $590^{\circ} \mathrm{C}$, and for each temperature four different nitriding times were used. This way twelve specimens were produced. Nitrided specimens were investigated with optical microscopy, electron probe micro-analysis and x-ray diffraction. The nitrogen depth concentration profiles, deduced from electron probe micro-analysis, in conjunction with results of optical microscopy, were used to determine the thickness of the nitrided layers, i.e. the diffusion depth of nitrogen. From the dependence of the nitrided layer thickness on process parameters (temperature and time) it was possible to deduce the law that governs the growth of the nitrided layer for $31 \mathrm{CrMoV} 9$ alloy steel. Through this law, then, it is possible to predetermine the layer thickness for every real process parameter in nitriding of $31 \mathrm{CrMoV} 9$ steel, which is very important for technological applications.
\end{abstract}

DOI: 10.12693/APhysPolA.130.83

PACS/topics: 61.05.cp, 81.65.Lp

\section{Introduction}

Nitriding is an industrial thermochemical surface treatment process by which the surface of various steels and alloys is enriched with nitrogen, which is introduced through nitrogen donating species. The main advantages of this process are the improvements in the surface properties of steels, such as high hardness, resistance to wear, fatigue and corrosion [1-3]. Gas nitriding [4] is one of the most versatile surface treatment processes with many advantages over the liquid and plasma nitriding. A precise process control of nitrogen uptake via the thermodynamic chemical potential of nitrogen in the gas phase is the main advantage of the gas nitriding method $[4,5]$. Controlling the nitriding process with a thermodynamic parameter makes it possible to produce nitriding layers that meet various technological requirements [5].

In recent years, the influence of the process parameters on the growth of the gas-nitrided layer of the 31CrMoV9 steel and characteristics of the nitrided layer have been studied $[1,5]$. Study of the kinetics of growth was performed by Efe [5] using common fitting procedures applied to the experimentally acquired data, which yielded values for the frequency factor and the activation energy of the nitriding process. In this work, the influence of the nitriding time and temperature on the nitrided layer growth of the gas-nitrided $31 \mathrm{CrMoV} 9$ steel was investigated in a series of experiments. Study of the kinetics of growth was also performed using a new direct and more intuitive approach, that consists in fitting all the experimentally determined thickness data, as a function of nitriding time and temperature, to a two-parameter equation. These parameters, which are related to the frequency factor and the activation energy of the nitriding

\footnotetext{
*corresponding author; e-mail: fisnik.aliaj@uni-pr.edu
}

process, are refined by the least square method until the equation best describes the experimental data. The obtained equation might then be used to describe the nitride layer growth for every process parameter in gasnitrided $31 \mathrm{CrMoV} 9$ steel, which might be of interest for technological applications.

The direct approach utilized in this work reduces the errors because it only requires one time regression, as compared with the common procedures usually encountered in literature, that require many regressions to calculate the frequency factor and the activation energy.

\section{Experimental details}

The effect of temperature and time on the growth of the nitrided layer and its characteristics for the gasnitrided $31 \mathrm{CrMoV} 9$ alloy steel was investigated in a series of experiments. The chemical composition of the 31CrMoV9 steel measured with spark emission spectrometer model JY-132F is shown in Table I. Disk shaped steel specimens with dimensions of $\varnothing 35 \times 10 \mathrm{~mm}$ were mechanically ground on $\mathrm{SiC}$ paper of successively finer grades, starting with 320 -grit and proceeding to 400-, and 600 -grit paper, using water to keep the specimens cool. Prior to gas nitriding, the steel specimens were first normalized in a $\mathrm{N}_{2}$ atmosphere at $860^{\circ} \mathrm{C}$ for $2 \mathrm{~h}$, followed by rapid cooling in oil, and then tempered at $630^{\circ} \mathrm{C}$ for $2 \mathrm{~h}$. After thermal treatment, the specimens were ultrasonically cleaned in acetone for 5 minutes, dried in hot air and then transferred to the actual nitriding environment. The gas nitriding was performed in air doped ammonia atmosphere at $510^{\circ} \mathrm{C}$ (for $16,36,64$ and $100 \mathrm{~h}$ ), $550^{\circ} \mathrm{C}$ (for 9, 16, 36 and $64 \mathrm{~h}$ ) and $590^{\circ} \mathrm{C}$ (for 4, 9, 16 and $36 \mathrm{~h}$ ). The nitriding atmosphere was controlled in such way, that the nitriding potentials were $3.4,3.0$ and $2.82 \mathrm{~atm}^{-1 / 2}$ at temperatures of 510,550 and $590^{\circ} \mathrm{C}$, respectively, providing the same nitrogen concentration on the surface of the steel specimens. After gas nitriding, 
the specimens were cut to obtain a cross-section, mounted in resin, and subsequently grinded and polished in the final polishing step with $1 \mu \mathrm{m}$ grains. In order to avoid damaging and rounding off at the edges upon crosssectional preparation, the specimens were protected by Ni-plating prior to mounting in resin. For metallographic examinations with optical microscopy (OM) each crosssectioned nitrided specimen was etched in a $2 \%$ Nital solution.

X-ray diffraction (XRD) method was applied for the identification of phases formed on the surfaces of the nitrided specimens. The measurements were performed with $\mathrm{Co}-\mathrm{K}_{\alpha}$ radiation by using a Seifert URD63 diffractometer in a conventional $\theta / 2 \theta$ Bragg-Brentano symmetrical geometry.

Nitrogen concentration-depth profiles of nitrided specimens were determined with electron probe microanalysis (EPMA) technique using a Joel JXA-8900 RL microanalyser operated at $U=20 \mathrm{kV}$. EPMA measurements were performed on polished cross-section of the nitrided specimens, perpendicular to the surface, starting at the surface and by moving in $5 \mu \mathrm{m}$ increments towards the depth of the specimens. Nitrogen concentration-depth profiles allowed us to determine the nitriding depth at each nitriding temperature and time, which was then used to describe the growth behaviour of the nitrided layer of $31 \mathrm{CrMoV} 9$ steel.

TABLE I

Chemical composition of 31CrMoV9 steel [wt.\%].

\begin{tabular}{c|c|c|c|c|c|c|c|c|c}
\hline \hline $\mathrm{C}$ & $\mathrm{Cr}$ & $\mathrm{Mn}$ & $\mathrm{V}$ & $\mathrm{Mo}$ & $\mathrm{Si}$ & $\mathrm{S}$ & $\mathrm{P}$ & $\mathrm{Al}$ & $\mathrm{Fe}$ \\
\hline 0.29 & 2.17 & 0.70 & 0.15 & 0.27 & 0.26 & 0.004 & 0.016 & 0.022 & balance
\end{tabular}

\section{Results and discussion}

Figure 1 shows the nitrogen concentration-depth profiles after the nitriding treatments at (a) $510^{\circ} \mathrm{C}$, (b) $550{ }^{\circ} \mathrm{C}$, and (c) $590^{\circ} \mathrm{C}$ of the $31 \mathrm{CrMoV} 9$ steel. For comparison in Fig. 1d are shown the OM of steel specimens nitrided at $590^{\circ} \mathrm{C}$. For all nitriding temperatures and times investigated in this work, the nitrided zone was composed of two layers: (i) a thin compound layer at the surface composed of $\gamma^{\prime}$ iron nitrides and (ii) a diffusion layer underneath the compound layer composed of $\mathrm{CrN}$ precipitates and cementite dispersed in the ferrite matrix.

In this work, the thickness of the nitrided layer was estimated as the depth at which the nitrogen content is almost negligible. Table II lists the estimated thickness values for each nitriding temperature and time. As it can be seen in Table II, there was a thickening of the nitriding layer upon increasing of the nitriding temperature and time. The thickness and the composition of a surface layer that develops during the nitriding process are affected by the type of the chemical reactions occurring at the sample surface, by the diffusivity of nitrogen in the treated material, the gas-mixture ratio, the process temperature, and the time [5].

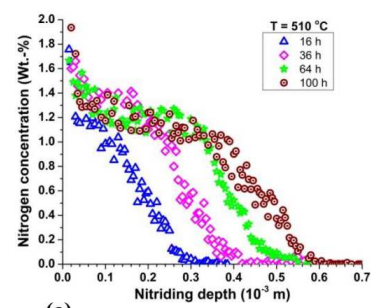

(a)


Fig. 1. Nitrogen concentration-depth profiles determined by EMPA for the nitrided $31 \mathrm{CrMoV} 9$ steel at: (a) $510^{\circ} \mathrm{C}$, (b) $550{ }^{\circ} \mathrm{C}$ and (c) $590{ }^{\circ} \mathrm{C}$. (d) Optical micrographs of the nitrided $31 \mathrm{CrMoV} 9$ steel specimens at $590^{\circ} \mathrm{C}$.

TABLE II

Nitriding parameters, nitriding layer thickness and temperature dependent diffusion coefficients of the gasnitrided 31CrMoV9 steel.

\begin{tabular}{c|c|c|c|c}
\hline \hline $\begin{array}{c}\text { Nitriding } \\
\text { temp. } \\
T\left[{ }^{\circ} \mathrm{C}\right]\end{array}$ & $\begin{array}{c}\text { Nitriding } \\
\text { time, } \\
t[\mathrm{~h}]\end{array}$ & $\begin{array}{c}\text { Nitriding } \\
\text { potential, } \\
K_{\mathrm{N}} \\
{\left[\mathrm{atm}^{-1 / 2}\right]}\end{array}$ & $\begin{array}{c}\text { Nitrided } \\
\text { layer } \\
\text { thickness, } \\
d[\mathrm{~mm}]\end{array}$ & $\begin{array}{c}\text { Diffusion } \\
\text { coefficient, } \\
D_{\mathrm{N}}\end{array}$ \\
\hline \multirow{5}{*}{510} & 16 & 3.4 & 0.27 & \\
& 36 & & 0.38 & 1.0909 \\
& 64 & & 0.51 & \\
& 100 & & 0.62 & \\
\hline \multirow{5}{*}{550} & 9 & & 0.26 & \\
& 16 & 3.0 & 0.34 & \multirow{2}{*}{1.8266} \\
& 36 & & 0.50 & \\
\hline \multirow{5}{*}{590} & 64 & & 0.64 & \\
& 9 & & 0.26 & \\
& 16 & 2.82 & 0.37 & \multirow{2}{*}{3.7043} \\
& 36 & & 0.49 & \\
& & & 0.68 &
\end{tabular}

From the thickness data of the nitrided layer, the growth kinetics of the layer can be deduced. Layer growth kinetics for a process is described by means of an equation that relates the thickness to the process parameters (time and temperature in case of gas nitriding), which for the gas nitriding is parabolic in nature and can be written as $[5,6]$

$$
d^{2}=D_{\mathrm{N}} t
$$

where $d$ is the thickness of the nitrided layer, $t$ is the nitriding time and $D_{\mathrm{N}}$ is the effective diffusion coefficient of nitrogen, which, considering an Arrhenius-type behavior is calculated according to 


$$
D_{\mathrm{N}}=D_{0} \exp \left(-E_{\mathrm{A}} / R T\right),
$$

where $T$ is the nitriding temperature (in Kelvin), $R$ is the universal gas constant, $D_{0}$ is the pre-exponential or frequency factor and $E_{\mathrm{A}}$ is the apparent activation energy of the nitriding process. In the literature $[5,6]$, the calculation of $D_{0}$ and $E_{\mathrm{A}}$ is usually carried out by firstly plotting the square of the experimental thickness data as a function of nitriding time for each investigated temperature. Then, the temperature dependent diffusion coefficients, $D_{\mathrm{N}}$, are calculated from the slope of the straight lines fitting the experimental data. The diffusion coefficients calculated in this manner are then plotted as a function of $1 / T$ and from the part of the plot showing a linear dependence the frequency factor, $D_{0}$, and activation energy, $E_{\mathrm{A}}$, are calculated.

In this work, however, a more direct and practical approach was utilized. The approach consists in fitting all the experimentally determined thickness data, as a function of nitriding time and temperature, directly with the equation

$$
d=a \exp (-b / 2 T) t^{1 / 2},
$$

by refining the parameters $a$ and $b$. The fitting procedure was done in the scientific graphing and data analysis program GraphPad Prism (ver. 6.01), which yielded the following results for the refining parameters: $a=$ $863.9 \times 10^{-3} \mathrm{~mm} / \mathrm{s}^{1 / 2}$ and $b=10.543 \mathrm{~K}$, respectively. Finally, the equation describing the layer growth kinetics of the gas-nitrided $31 \mathrm{CrMoV} 9$ steel is as follows:

$$
d=863.9 \times 10^{-3} \exp (-10.543 / 2 T) t^{1 / 2} .
$$

In Eq. (4), $d$ is given in $\mathrm{mm}, t$ in $\mathrm{s}$ and $T$ in $\mathrm{K}$. The experimental thickness data and the curves obtained from Eq. (4) are shown in Fig. 2, from which it can be seen that there is an excellent agreement. The Eq. (3) is just a combination of Eqs. (1) and (2), therefore the existing relationship between the parameters $a$ and $b$ and the parameters $D_{0}$ and $E_{A}$, respectively, gives the means to calculate the latter. The relationship between the parameters is: $a=D_{0}^{1 / 2}$ and $b=E_{\mathrm{A}} / R$. Thus, the pre-exponential factor and the activation energy calculated by this approach are $D_{0}=7.46 \times 10^{-3} \mathrm{~cm}^{2} / \mathrm{s}$ and $E_{\mathrm{A}}=87.7 \pm 5.1 \mathrm{~kJ} / \mathrm{mol}$. The obtained activation energy for the nitriding process is somewhat lower than the value reported by Efe [5], of $150 \mathrm{~kJ} / \mathrm{mol}$ for gas nitrided $31 \mathrm{CrMoV} 9$ steel, but is in excellent agreement with the value reported by Hernandez, et al. [7], of $83.1 \mathrm{~kJ} / \mathrm{mol}$ for gas-nitrided X38CrMoV5.1 steel, and with the value reported by Keedam, et al. [8, 9], of $77.9 \mathrm{~kJ} / \mathrm{mol}$ for pure iron. On the contrary, the value of $D_{0}$ was found to be higher $\left(7.46 \times 10^{-3} \mathrm{~cm}^{2} / \mathrm{s}\right)$ than that reported by Hernandez, et al. [7] $\left(1.03 \times 10^{-3} \mathrm{~cm}^{2} / \mathrm{s}\right)$ and by Keddam, et al. $[8,9]\left(6.6 \times 10^{-3} \mathrm{~cm}^{2} / \mathrm{s}\right)$. The observed differences between our results and the results by Efe [5] for the activation energy are probably due to the different nitriding conditions used.

It is a firm belief of the authors, that the direct approach would reduce the errors when calculating the $D_{0}$ and $E_{\mathrm{A}}$ because it only required one time regression, as compared with the common procedures usually encountered in literature, that require many regressions to calculate the $D_{0}$ and $E_{\mathrm{A}}$. Because the pre-exponential factor is very sensitive to the scattering of data, we will discuss errors only pertaining to the activation energy.

In order to check our statements regarding the direct approach utilized in this work, we have also performed the calculations as per common procedures found in the literature. The temperature dependent diffusion coefficients, $D_{\mathrm{N}}$, which were obtained by fitting Eq. (1) to the experimental data, are shown in Table II. Next, the frequency factor, $D_{0}$, and the activation energy, $E_{\mathrm{A}}$, were calculated from the intercept and the slope, respectively, of the straight line fitting the $\log D_{\mathrm{N}}$ vs. $1000 / T$ data. Thus calculated values are $E_{\mathrm{A}}=85.6 \pm 10.2 \mathrm{~kJ} / \mathrm{mol}$ and $D_{0}=5.36 \times 10^{-3} \mathrm{~cm}^{2} / \mathrm{s}$, which are slightly lower than the values obtained by the direct approach, but are within the error limits. However, the estimated standard error for the activation energy obtained by the common approach is two times higher than the standard error obtained by the direct approach, clearly demonstrating our expectations regarding the reduction of the estimated errors. By combining Eqs. (1) and (2) and by substituting the newly calculated values of $E_{\mathrm{A}}$ and $D_{0}$, then similarly to Eq. (4) the following is obtained for the common approach:

$$
d=732.1 \times 10^{-3} \exp (-10.295 / 2 T) t^{1 / 2} .
$$

Finally, the experimental nitride thickness data were used to compare the two equations, (4) and (5), i.e. the two approaches. The percentage average relative error (PARE), calculated according to

$$
\text { PARE }=\frac{1}{N} \sum_{i=1}^{N}\left(\frac{\left|d_{\text {Exp. }}-d_{\text {Cal. }}\right|}{d_{\text {Exp. }}}\right)_{i} \times 100 \%,
$$

was used as a measure to compare the two approaches. In Eq. (6), $d_{\text {Exp }}$ represents the experimental data, $d_{\text {Cal }}$ represents the data calculated by Eqs. (4) or (5), and $N$ is the number of the experimental data points. Table III shows the PARE results of the two approaches, from which it can be seen that the error calculated by the direct approach is smaller than that calculated by the common approach, again demonstrating what was expected regarding the reduction of errors. Because the errors calculated by the direct approach are much smaller than in the common approach, in Fig. 2 are also plotted some predicted lines (for nitriding temperatures other than the ones investigated in this work), which might be of interest for technological applications.

TABLE III

Comparison of the calculation error, PARE, from the direct approach and from the common approach.

\begin{tabular}{c|c|c}
\hline \hline & $\begin{array}{c}\text { Calculated from } \\
\text { the common } \\
\text { approach, Eq. (5) }\end{array}$ & $\begin{array}{c}\text { Calculated from } \\
\text { the direct } \\
\text { approach, Eq. (4) }\end{array}$ \\
\hline PARE (\%) & 9.2 & 8.4
\end{tabular}




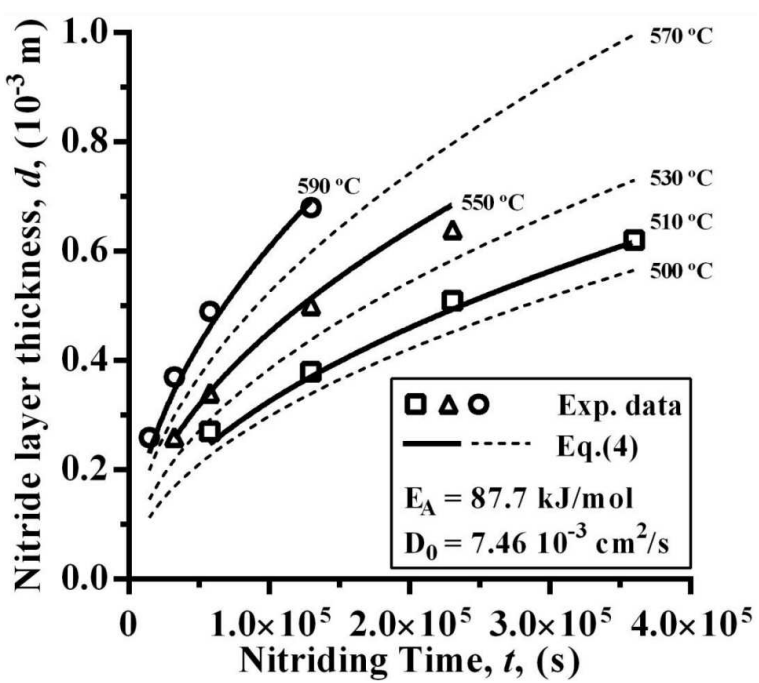

Fig. 2. The nitride layer thickness as a function of temperature and time determined from EMPA nitrogen depth profiles (data points) and as determined by fitting to these data of Eq. 4 (solid and dashed lines).

\section{Conclusions}

The gas-nitriding of the $31 \mathrm{CrMoV} 9$ alloy steel was carried out between 510 and $590^{\circ} \mathrm{C}$, and for each temperature four different nitriding times were chosen. Based on the results of EPMA, OM, and XRD, the following conclusions can be made on the effects that nitriding time and temperature have on the growth of the nitrided layers:

- For all nitriding temperatures and times investigated in this work, the nitrided zone is composed of two layers: (i) a thin compound layer at the surface composed of $\gamma^{\prime}$ iron nitrides and (ii) a diffusion layer underneath the compound layer composed of $\mathrm{CrN}$ precipitates and cementite dispersed in the ferrite matrix.
- The thickening of the nitrided layer is observed upon increasing of the nitriding temperature and time.

- Study of the kinetics of growth performed by using the direct approach, which consisted in fitting all the experimentally determined thickness data to a two-parameter equation, proved successful in determining the pre-exponential factor and the activation energy of the nitriding process. The pre-exponential factor and the activation energy of nitriding of $31 \mathrm{CrMoV} 9$ steel were found to be $7.46 \times 10^{-3} \mathrm{~cm}^{2} / \mathrm{s}$ and $87.7 \mathrm{~kJ} / \mathrm{mol}$, respectively.

- The direct approach reduces the errors because it only requires one time regression, as compared with the common procedures usually encountered in literature that require many regressions to calculate the frequency factor and the activation energy.

\section{References}

[1] M. Emami, H.M. Ghasemi, J. Rassizadehghani, Surface Eng. 26, 168 (2010).

[2] F.T. Hoffmann, P. Mayr, ASM Handbook: Friction, Lubrication, and Wear Technology, OH: ASM International, Metal Park 1992, Vol. 18, p. 1783.

[3] N. Syla, Sh. Klinaku, F. Aliaj, Res. J. Appl. Sci. 5, 444 (2010).

[4] H. Selg, Ph.D., University of Stuttgart, Germany, 2012.

[5] G.C. Efe, Mater. Technol. 48, 827 (2014).

[6] C.E. Pinedo, W.A. Monteiro, Surf. Coat. Technol. 179, 119 (2004).

[7] M. Hernandez, M.H. Staia, E.S. Puchi-Carbera, Surf. Coat. Technol. 202, 1935 (2008).

[8] M. Keddam, M.E. Djeghlal, L. Barrallier, Mater. Sci. Eng. A 378, 475 (2004).

[9] M. Keddam, M.E. Djeghlal, L. Barrallier, Appl. Surf. Sci. 242, 369 (2005). 